\title{
Assessment of Patient's Expectations on Removable Partial Denture Prosthesis
}

\author{
Vigneshwaran Ravichandran ${ }^{1}$ and Dhanraj Ganapathy ${ }^{2}$ \\ ${ }^{1}$ Saveetha Dental College and Hospitals Saveetha Institute of Medical \\ and Technical Sciences Saveetha University, Chennai, India \\ ${ }^{2}$ Professor and Head Department of Prosthodontics Saveetha Dental College and Hospitals \\ Saveetha Institute of Medical and Technical Sciences Saveetha University, Chennai, India.
}

\section{ABSTRACT}

Tooth loss can have negative impacts on facial appearance, speech, and mastication. The replacement of missing teeth by appropriately designed prosthesis is in demand and is required to maintain a good health status and normal life. There are several modalities of treatment for rehabilitation of partial edentulous patients. These include implant supported prosthesis, teeth supported bridges and removable partial denture. RPDs are applied to restore facial form and masticatory function after loss of natural teeth. There is a lack of available information on patient satisfaction and complaints with RPD . The purpose of this retrospective study was to investigate the expectation level on removable partial denture among patients in OP of saveetha dental college. A set of 15 questionnaires in regards to assess the level of patients expectations on removable partial denture prosthesis were taken. 100 random participants of independent age and sex were selected from OP of Saveetha dental college and asked them to fill the questionnaire. The survey was conducted on an online forum. The results were obtained and analysed statistically.Among the 100 participants , 52 of them are male and 48 of them are female in which more than $50 \%$ of participants are above 40 years old . More than 70\% of the participants have edentulousness or missing teeth. In which $40 \%$ of them have previous denture experience. The major difficulties of the participants with the edentulousness or missing teeth are discomfort in mastication (60\%), phonetic difficulties (56\%) and Aesthetical problems (47\%). The average level of expectation regarding the fitness of removable partial denture is 3.55/5. The average level of expectation regarding the functional limitation of RPD 3.38/5. The average level of expectation regarding the phonetical comfortness of RPD is 3.39/5 and the average level of expectation on the aesthetic comfortness is 3.48/5. More than 75\% of the participants wish to undergo removable denture prosthesis with an average overall satisfactory level of 3.58/5. Within the limitations of this study, the majority of participants have high levels of expectation with their removable partial dentures treatment. The most common expectation was fitness and aesthetic issues, which suggests that dental treatments with removable partial denture should be applied with care when patients have high aesthetics, phonetical and functional concerns.

KEY WORDS: REMOVABLE PARTIAL DENTURE ; PATIENT'S EXPECTATIONS ; FUNCTIONAL EXPECTATIONS ; AESTHETICAL EXPECTATIONS ; PHONETICAL EXPECTATIONS.

\section{ARTICLE INFORMATION}

*Corresponding Author: dhanraj@saveetha.com

Received 18th June 2020 Accepted after revision 13th August 2020

Print ISSN: 0974-6455 Online ISSN: 2321-4007 CODEN: BBRCBA

Thomson Reuters ISI Web of Science Clarivate Analytics USA and Crossref Indexed Journal

$$
1 \text { Clarivate } \begin{gathered}
\text { Analytics } \\
\text { Crossef }
\end{gathered}
$$

NAAS Journal Score 2020 (4.31) SJIF: 2020 (7.728)

A Society of Science and Nature Publication,

Bhopal India 2020. All rights reserved.

Online Contents Available at: http//www.bbrc.in/

Doi: http://dx.doi.org/10.21786/bbrc/13.7/25 


\section{INTRODUCTION}

Tooth loss can have negative impacts on facial appearance, speech, and mastication. The replacement of missing teeth by appropriately designed prosthesis is in demand and is required to maintain a good health status and normal life. In many countries, oral health parameters have shown gradual improvement and the rate of edentulism is decreasing, which could lead to a reduction in the need for dentures. However, it is estimated that, despite the decline in edentulism rates, the number of edentulous patients will increase until the year 2020, due to an increase of the elderly population (Allen and McMillan, 2003; Carlsson, 2006). Thus, an interest in dental implants has increased rapidly over the last two decades. However, the vast majority of edentulous persons still have to accept conventional dentures, mainly due to economic factors. This outcome is attributed to the fact that toothless individuals usually belong to the poorest population stratum and have no access to treatment with implants. Therefore, most prosthetic work undertaken by dentists still consists of conventional crowns and dentures. There are several modalities of treatment for rehabilitation of partial edentulous patients. These include implant supported prosthesis, teeth supported bridges and removable partial denture.

RPDs are applied to restore facial form and masticatory function after loss of natural teeth . Acrylic polymers (polymethyl methacrylate[PMMA]) and metallic (chrome cobalt alloys) materials are routinely used. However due to the considerably low cost, ease of manipulation and utilisation of inexpensive equipment, acrylic denture bases are the most popular material for RPD framework fabricationThus, it is important to note that conventional dentures also provide benefits for edentulous patients, providing aesthetics and some function, as well as being socially acceptable for the replacement of missing teeth (Carlsson, 2006; Leles et al., 2008). Some of the advantages of removable dental prosthesis (RDP) therapy vs conventional or implant-supported fixed bridges are that RDPs usually cost less and are easier to clean (Cosme et al., 2006). Considering that patient satisfaction is the ultimate objective during oral rehabilitation, it is interesting to note that few studies have been conducted in order to verify and understand the factors that affect this satisfaction (Carlsson, 2006).

Chewing ability, comfort, aesthetics and retention are important factors for acceptance by RDP wearers (celebic and Knezovic-Zlataric, 2003; Mazurat and Mazurat, 2003). For some patients, the overall satisfaction with RDP is related to comfort and the ability to chew. For other individuals, aesthetics and reten- tion seem to be the most important factors (Zlataric and Celebic, 2008). Thus, while dentures are constructed, great emphasis is placed on technical aspects that relate to the denture's quality, which seems to play a role in the quality of life relating to oral health of RDP wearers (Inukai et al., 2008). Furthermore, it is also important to take into consideration the personality, attitude and motivation for
RDP use, which also may influence patient satisfaction (Cosme et al., 2006; Carlsson, 2009). Therefore, satisfaction with dentures is multifactorial, involving technical aspects and also those that relate to the patient (Carlsson, 2006, 2009; Bellini et al., 2009). It is important to note that patients and health professionals evaluate their expectations and satisfac- tion with removable dentures therapy in completely different ways. This fact can lead to conflict and a deterioration of the patient/ professional relationship (Marachlioglou et al., 2010), which may also influence patient satisfaction with their dentures (Carlsson, 2009).

Although RPDs are a non-invasive and reversible treatment option, with a more acceptable cost and easier oral hygiene techniques in most cases, they are associated with several oral complaints, such as speech, mastication, pain, and aesthetic issues (Khan, Khan and Others, 2015). There is a lack of available information on patient satisfaction and complains with RPD . In the light of the previous information, the present study aims to assess the level of patient's expectations on removable partial denture prosthesis

Previously our department has published extensive research on various aspects of prosthetic dentistry ('Evaluation of Corrosive Behavior of Four Nickelchromium Alloys in Artificial Saliva by Cyclic Polarization Test:An in vitro Study', 2017; Ganapathy, Kannan and Venugopalan, 2017; Jain, 2017a, 2017b; Ranganathan, Ganapathy and Jain, 2017; Ariga et al., 2018; Gupta, Ariga and Deogade, 2018; Anbu et al., 2019; Ashok and Ganapathy, 2019; Duraisamy et al., 2019; Varghese, Ramesh and Veeraiyan, 2019), this vast research experience has inspired us to research about the assessment of patient's expectations on removable partial denture prosthesis .

\section{MATERIAL AND METHODS}

The cross-sectional descriptive and analytical study design was used to assess the patient's expectations on removable partial denture prosthesis. 100 participants from OP department of Saveetha dental college of independent age and sex by random sampling method were selected for the study . A set of 15 questionnaires was designed and prepared, which was later reviewed by the experts in this field of study. The questionnaire consists of Socio-demographic information of the respondents such as Age, Gender, also sections on thoughts of the participants on removable partial denture prosthesis and grading their level of expectations. The Survey was conducted on an online forum . The results were obtained and statistically analysed.

\section{RESULTS AND DISCUSSION}

Among the 100 participants, $52 \%$ of them were Male and $48 \%$ of them were Female in which more than 50 $\%$ of participants were above 40 years old . $21 \%$ of the participants were less than 30 yrs old, $23 \%$ were 30 to 40 yrs old, $16 \%$ were 40 to 50 yrs old, $23 \%$ were 50 to 
60 yrs old and $17 \%$ were more than 60 yrs old. More than $71 \%$ of the participants have edentulousness or missing teeth and $29 \%$ don't have edentulousness or missing teeth. $39 \%$ of the participants have previous denture experience.

Figure 1: The Pie chart represents the percentage distribution of age of the participants. More than $50 \%$ of participants were above 40 years old. $21 \%$ of the participants were less than $30 \mathrm{yrs}$ old, $23 \%$ were 30 to 40 yrs old, $16 \%$ were 40 to 50 yrs old, $23 \%$ were 50 to 60 yrs old and $17 \%$ were more than 60 yrs old

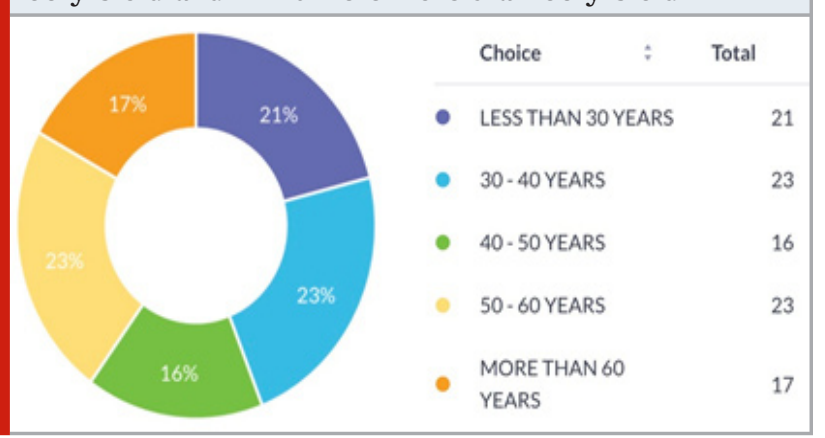

Figure 2: The Pie chart represents the percentage distribution of gender of the participants. Among the total participants, $52 \%$ of them were Male and $48 \%$ of them were Female

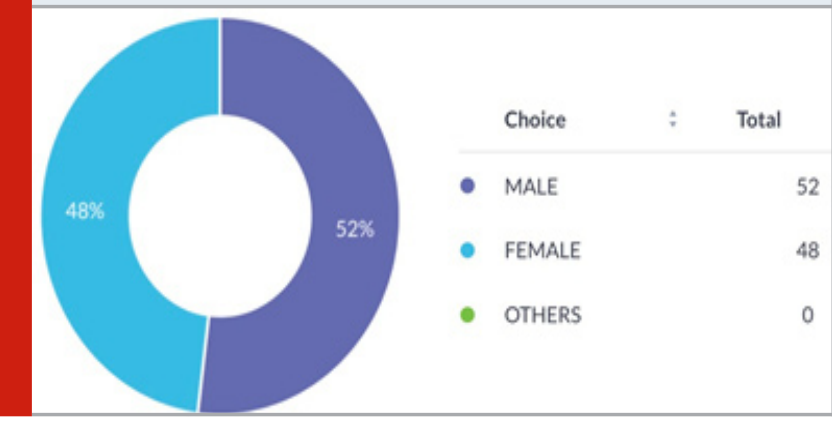

Figure 3: The Pie chart represents the percentage distribution of presence of edentulousness or missing teeth in the participants. More than $71 \%$ of the participants have edentulousness or missing teeth and $29 \%$ don't have edentulousness or missing teeth

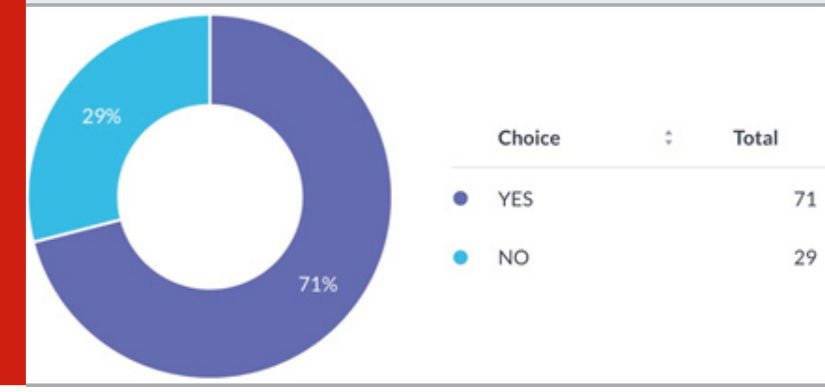

$50 \%$ of the participants have family members who underwent TPD. $44 \%$ of the participants were having the view that the TPD was cost efficient and $56 \%$ of them thought that it was not affordable. $32 \%$ of the participants expect the outcome of TPD as a temporary replacement , $38 \%$ expect the outcome as temporary and comfortable replacement and $30 \%$ expect the outcome as uncomfortable replacement.

Figure 4: The pie chart represents the percentage distribution of participants having family members who underwent TPD. $50 \%$ of the participants have family members who underwent TPD and $50 \%$ were not having such family members with TPD

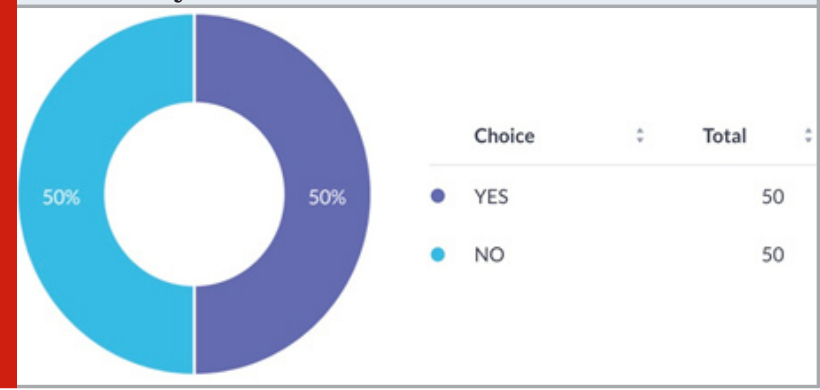

Figure 5: The Pie chart represents the percentage distribution of expectation of the participants on the outcome of TPD. $32 \%$ of the participants expect the outcome of TPD as a temporary replacement, $38 \%$ expect the outcome as temporary and comfortable replacement and $30 \%$ expect the outcome as uncomfortable replacement

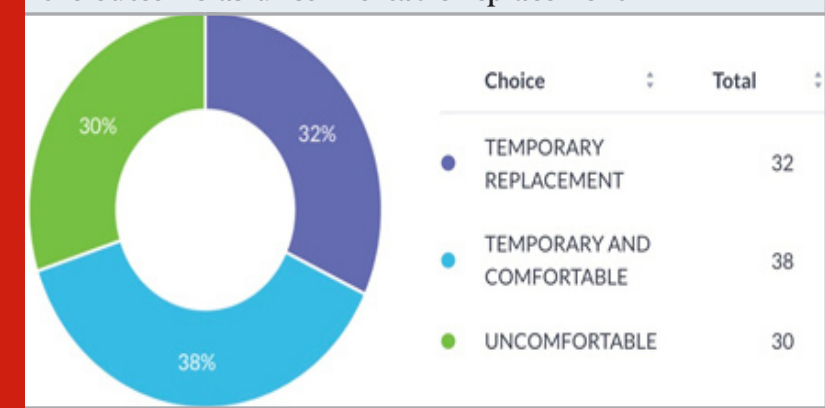

Figure 6: The Pie chart represents the percentage distribution of the participant's view regarding the cost of TPD. $44 \%$ of the participants were having the view that the TPD was cost efficient and $56 \%$ of them thought that it was not affordable

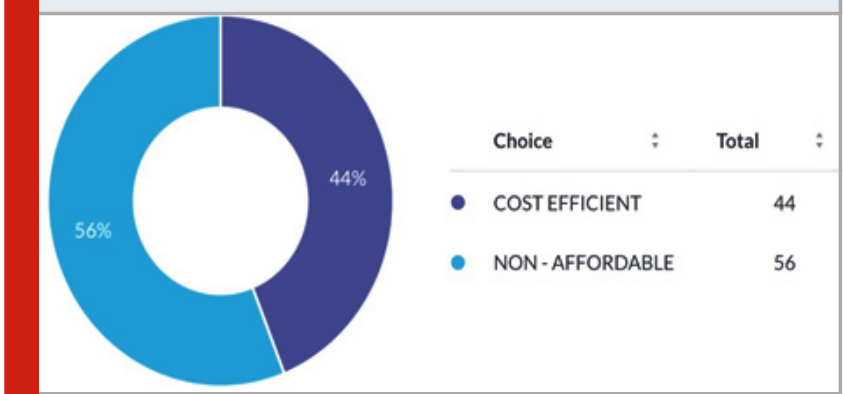

The major difficulties of the participants with the edentulousness or missing teeth are discomfort in mastication (60\%), phonetic difficulties (56\%) and 
Aesthetical problems (47\%). The average level of expectation regarding the fitness of removable partial denture is 3.55/5. The average level of expectation regarding the functional limitation of RPD 3.38/5. The average level of expectation regarding the phonetical comfortness of RPD is 3.39/5 and the average level of expectation on the aesthetic comfortness is 3.48/5. More than $75 \%$ of the participants wish to undergo removable denture prosthesis with an average overall satisfactory level of 3.58/5.

Figure 7: The Pie chart represents the percentage distribution of participants having any previous denture experience. $39 \%$ of the participants have previous denture experience. $61 \%$ don't have any previous denture experience

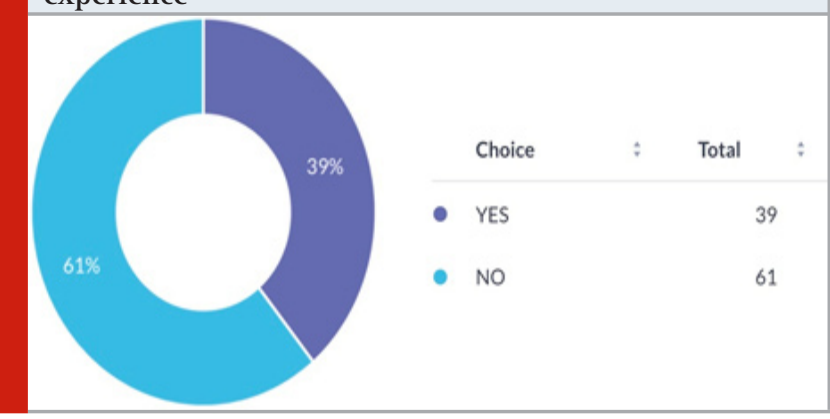

Figure 8: The Pie chart represents the percentage distribution of difficulties experienced by the participants with edentulousness or missing teeth. The major difficulties of the participants with the edentulousness or missing teeth are discomfort in mastication $(60 \%)$, phonetic difficulties (56\%) and Aesthetical problems (47\%)

\begin{tabular}{ll} 
Choice & \multicolumn{1}{|c|}{$\begin{array}{l}\text { Total } \\
\text { DISCOMFORT IN } \\
\text { MASTICATION } \\
\text { PHONETICALLY } \\
\text { DIFFICULTIES } \\
\text { AESTHETICAL } \\
\text { PROBLEMS } \\
\text { NONE }\end{array}$} \\
\hline
\end{tabular}

Figure 9: The Pie chart represents the percentage distribution of the willingness of the participants to undergo and consider TPD. More than $29 \%$ of the participants wish to undergo removable denture prosthesis and $25 \%$ were not willing for TPD and $46 \%$ of the participants answered maybe

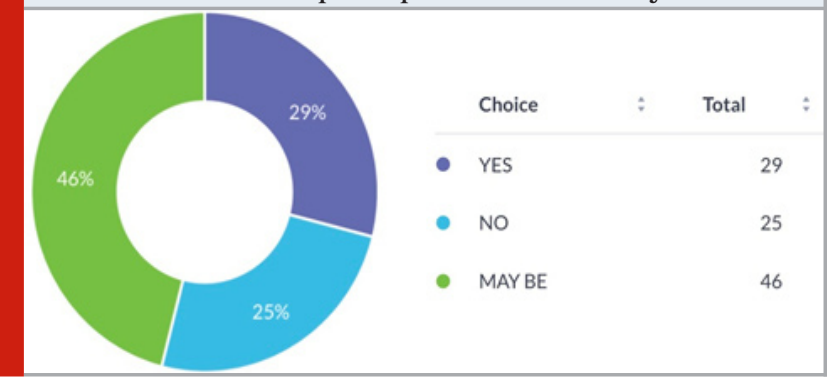

146
Figure 10: The bar graph represents the average level of expectations of the participants on Removable partial denture prosthesis. The $\mathrm{X}$ - axis represents the various different expectations and $\mathrm{Y}$ - axis represents the range of expectation (Out of 5). The average level of expectation regarding the fitness of removable partial denture is 3.55/5. The average level of expectation regarding the functional limitation of RPD 3.38/5. The average level of expectation regarding the phonetical comfortness of RPD is 3.39/5 and the average level of expectation on the aesthetic comfortness is $3.48 / 5$. The average level of overall expectation on Removable denture prosthesis is $3.58 / 5$

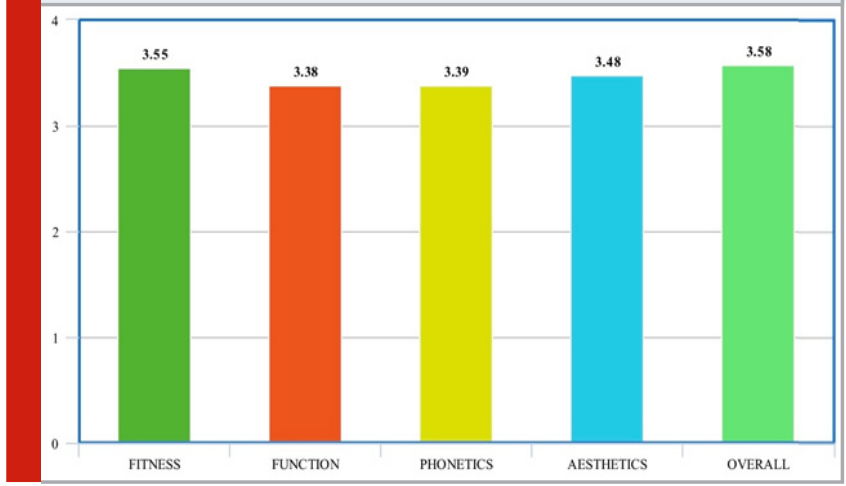

\section{CONCLUSION}

Within the limitations of this study, the majority of participants have high levels of expectation with their removable partial dentures treatment. The most common expectation was fitness and aesthetic issues, which suggests that dental treatments with removable partial denture should be applied with care when patients have high aesthetics, phonetical and functional concerns .

\section{ACKNOWLEDGEMENTS}

We thank Saveetha University for their support and suggestions.

Conflict of Interest: The authors declare that there is no conflict of interest

\section{REFERENCES}

Allen, P. F. and McMillan, A. S. (2003) 'A review of the functional and psychosocial outcomes of edentulousness treated with complete replacement dentures', Journal , 69(10), p. 662.

Anbu, R. T. et al. (2019) 'Comparison of the Efficacy of Three Different Bone Regeneration Materials: An Animal Study', European journal of dentistry, 13(1), pp. 22-28.

Ariga, P. et al. (2018) 'Determination of Correlation of Width of Maxillary Anterior Teeth using Extraoral and Intraoral Factors in Indian Population: A Systematic Review', World Journal of Dentistry, 9(1), pp. 68-75. Ashok, V. and Ganapathy, D. (2019) 'A geometrical 
method to classify face forms', Journal of oral biology and craniofacial research, 9(3), pp. 232-235.

Bellini, D. et al. (2009) 'Patients' expectations and satisfaction of complete denture therapy and correlation with locus of control', Journal of oral rehabilitation, 36(9), pp. 682-686.

Carlsson, G. E. (2006) 'Facts and fallacies: an evidence base for complete dentures', Dental update, 33(3), pp. 134-6, 138-40, 142.

Carlsson, G. E. (2009) 'Critical review of some dogmas in prosthodontics', Journal of prosthodontic research, 53(1), pp. 3-10.

Celebic, A. and Knezovic-Zlataric, D. (2003) 'A comparison of patient's satisfaction between complete and partial removable denture wearers', Journal of dentistry, 31(7), pp. 445-451.

Cosme, D. C. et al. (2006) 'Functional evaluation of oral rehabilitation with removable partial dentures after five years', Journal of applied oral science: revista FOB, 14(2), pp. 111-116.

Duraisamy, R. et al. (2019) 'Compatibility of Nonoriginal Abutments With Implants: Evaluation of Microgap at the Implant-Abutment Interface, With Original and Nonoriginal Abutments', Implant dentistry, 28(3), pp. 289-295.

Evaluation of Corrosive Behavior of Four Nickelchromium Alloys in Artificial Saliva by Cyclic Polarization Test:An in vitro Study' (2017) World Journal of Dentistry, 8(6), pp. 477-482.

Ganapathy, D. M., Kannan, A. and Venugopalan, S. (2017) 'Effect of Coated Surfaces influencing Screw Loosening in Implants: A Systematic Review and Meta-analysis', World Journal of Dentistry, 8(6), pp. 496-502.

Gupta, P., Ariga, P. and Deogade, S. C. (2018) 'Effect of Monopoly-coating Agent on the Surface Roughness of a Tissue Conditioner Subjected to Cleansing and Disinfection: A Contact Profilometric Study', Contemporary clinical dentistry, 9(Suppl 1), pp. S122S126.

Inukai, M. et al. (2008) 'Does removable partial denture quality affect individuals' oral health?', Journal of dental research, 87(8), pp. 736-739.

Jain, A. R. (2017a) 'Clinical and Functional Outcomes of Implant Prostheses in Fibula Free Flaps', World Journal of Dentistry, 8(3), pp. 171-176.

Jain, A. R. (2017b) 'Prevalence of Partial Edentulousness and Treatment needs in Rural Population of South India', World Journal of Dentistry, 8(3), pp. 213-217.

Khan, M., Khan, A. and Others (2015) 'ORAL COMPLAINTS AND LEVEL OF SATISFACTION AMONG THE REMOVABLE DENTURE WEARERS A STUDY', Pakistan Oral \&t Dental Journal. AsiaNet Pakistan (Pvt) Ltd., 35(1). Available at: http://search.proquest.com/ openview/09601955aef2c9cee83c9ae396d251bc/1?p q-origsite $=$ gscholarCtcbl $=616533$.

Leles, C. R. et al. (2008) 'Assessing perceived potential outcomes of prosthodontic treatment in partial and fully edentulous patients', Journal of oral rehabilitation, 35(9), pp. 682-689.

Marachlioglou, C. R. M. Z. et al. (2010) 'Expectations and final evaluation of complete dentures by patients, dentist and dental technician', Journal of oral rehabilitation, 37(7), pp. 518-524.

Mazurat, N. M. and Mazurat, R. D. (2003) 'Discuss Before Fabricating: Communicating the Realities of Pa rtial De ntu re T herap y. Pa rt I: Patient Ex pectations', Journal , 69(2), pp. 90-94.

Ranganathan, H., Ganapathy, D. M. and Jain, A. R. (2017) 'Cervical and Incisal Marginal Discrepancy in Ceramic Laminate Veneering Materials: A SEM Analysis', Contemporary clinical dentistry, 8(2), pp. 272-278.

Varghese, S. S., Ramesh, A. and Veeraiyan, D. N. (2019) 'Blended Module-Based Teaching in Biostatistics and Research Methodology: A Retrospective Study with Postgraduate Dental Students', Journal of dental education, 83(4), pp. 445-450.

Zlataric, D. K. and Celebic, A. (2008) 'Factors related to patients' general satisfaction with removable partial dentures: a stepwise multiple regression analysis', The International journal of prosthodontics, 21(1), p. 86. 